\title{
El mito de la Edad de Oro en el Quijote y en La tempestad de William Shakespeare
}

\section{María Stoopen GALÁN Universidad Nacional Autónoma de México}

\begin{abstract}
El mito de la Edad de Oro, un tópico renacentista de procedencia clásica, es recreado tanto en el Quijote de 1605 como en La tempestad, representada por primera vez en 1611. En este artículo se exploran las fuentes literarias, cercanas y remotas, de la alocución de don Quijote ante los cabreros $(Q \mathrm{I}, 11)$ y la de Gonzalo ante los nobles que han naufragado en una isla desconocida (Tmp. 2, 1). Se destacan también la función de los discursos de los personajes, el papel que desempeñan los receptores ante quienes se pronuncian y la relación del mito con el pensamiento utópico renacentista.
\end{abstract}

Palabras ClaVE: mito de la Edad de Oro, Quijote, La tempestad, fuentes literarias, pensamiento utópico renacentista.

The myth of the Golden Age, a Renaissance topic originated in the Classic culture, is recreated in Don Quixote (1605) as well in The Tempest, performed for the first time in 1611 . This paper explores nearby and remote literary sources of Don Quixote's discourse before the goatherds $(Q \mathrm{I}, 11)$ and Gonzalo's before the nobles who were shipwrecked on an unknown island (Tmp. 2, 1). It also highlights the function of the characters' speeches, the role of the listeners to whom they are addressed and the relation of the myth to Renaissance utopian thinking.

KeY words: Golden Age myth, Don Quixote, The Tempest, literary sources, renaissance utopian thinking.

Todos los pueblos que tienen historia tienen un paraíso, un estado de inocencia, una edad de oro;

y hasta cada hombre tiene un paraíso, su edad de oro, que él recuerda con más o menos fervor según el grado que entre en su carácter el elemento poético.

\section{FRIEDRICH SCHILLER}

El mito de la Edad de Oro, un locus comunis desde la antigüedad clásica (Traver Vera, 2001), fue recreado en el Renacimiento por poetas, narradores, ensayistas y dramaturgos. Don Quijote pronuncia un discurso con el tema frente a un grupo de cabreros 
(I, 11) y en La tempestad, ${ }^{1}$ la última obra dramática escrita por William Shakespeare y representada en $1611,{ }^{2}$ Gonzalo, un viejo y honrado consejero del rey de Nápoles, lo dirige a un grupo de nobles provenientes de Italia en la isla en donde naufraga la nave en que viajaban (Shakespeare, 2011). Aquí me propongo recoger las fuentes principales de las que proviene el mito en cada una de las obras y analizar después la función que cumple en ellas con respecto a la situación en que uno y otro personaje lo recrea, así como el papel que desempeñan los receptores en relación con los ideales contenidos en él, y el vínculo de los discursos respectivos con el desarrollo de un pensamiento utópico en el Renacimiento.

El mito se conoce desde la antigüedad griega y es recogido por Hesíodo en Los trabajos y los días ( ca. siglo VIII a. C.); sin embargo, la versión más difundida en el Renacimiento es la de las Metamorfosis de Ovidio, aunque también se propagó por medio de las Geórgicas I y II y la Égloga IV de Virgilio, poemas que dan origen a la poesía bucólica y al género pastoril renacentistas. Harry Levin resume de esta manera los avatares del mito en la cultura occidental:

Si Hesíodo fue el primero en enunciar nuestro mito. Si Arato lo proveyó de una protagonista femenina, Virgilio lo reorientó tanto geográfica como cronológicamente cuando lo aclimató en Italia. Fue, sin embargo, su contemporáneo más joven, Ovidio, quien lo cristalizó en un tópico, quien reorganizó sus elementos tradicionales en una pieza retórica mayor que sería imitada, plagiada, parafraseada, parodiada, reinterpretada, controvertida, deformada y metamorfoseada de muchas maneras por los escritores... (19). ${ }^{3}$

Numerosos y muy completos son los estudios dedicados a rastrear las fuentes del discurso de la Edad de Oro en el Quijote. ${ }^{4}$ Aquí tomaré como base la investigación de Ángel J. Traver Vera, quien recoge los motivos fundamentales del tópico y aquellos que son recreados en la versión de Cervantes. El autor sostiene que "el discurso [de don Quijote] incardina gran parte de la parafernalia temática de la Edad de Oro sin un orden preciso, con la misma aleatoriedad que los arquetipos latinos y renacentistas más

${ }^{1}$ Agradezco a Alfredo Michel Modenessi haberme facilitado una copia de su versión de La tempestad en español, así como los buenos oficios de Luz Aurora Pimentel en conseguirla para ser utilizada en el presente trabajo.

${ }^{2}$ El Quijote fue traducido al inglés en 1612 por Thomas Shelton de la edición de Bruselas de 1607, y La tempestad se estrenó ante el rey de Inglaterra Jacobo I en 1611. Por lo tanto, uno no es referente del otro aunque comparten ese tema en común y presentan una gran cercanía temporal.

3 "If Hesiod first enunciated our myth, if Aratus endowed it with a feminine protagonist, Vergil reoriented it, both geographically and chronologically, when he acclimatized it to Italy. But it was his younger contemporary, Ovid, who crystallized it into a topos, who realigned its traditional elements in a grandly rhetorical set-piece that would be imitated, plagiarized, paraphrased, parodied, reinterpreted, controverted, distorted, and metamorphosed into so many shapes by the writers..." (Mi traducción.)

${ }^{4}$ Destacan José Antonio Maravall (169-235) y Geoffrey L. Stagg (71-90). Á. J. Traver Vera proporciona una exhaustiva y minuciosa bibliografía tanto de las fuentes cervantinas como de los estudios dedicados al discurso sobre la Edad de Oro en el Quijote. 
conspicuos... En general, los autores latinos como los renacentistas imbricaban sus motivos sobre otros, ya que muchos por naturaleza eran compatibles" (88).

Lo mismo podría decirse de la alocución de Gonzalo en La tempestad. Sin embargo, aunque William Shakespeare haya sido también lector de las Metamorfosis, ${ }^{6}$ los críticos que han comentado la presencia del mito en la obra dramática coinciden en establecer el ensayo "Los caníbales" de Montaigne como el referente textual inmediato del discurso del consejero regio: "La mayor parte de sus exclusiones [las inversiones de las costumbres europeas] — asegura Harry Levin — siguen la lista de Montaigne [...] haciéndose eco de la fraseología de la traducción de Floro [1553-1625]". ${ }^{7}$

Importa ahora destacar ciertas características ficcionales que constituyen la arquitectura particular de cada una de las obras. Si en el Quijote podemos distinguir por lo menos dos planos narrativos: el realista y el imaginario caballeresco, instituido por el hidalgo, en La tempestad se imbrican asimismo el plano realista, de los conflictos humanos, y el de la magia bajo el poder de Próspero, capaz de manipular tanto los eventos del primero como las acciones de los seres fantásticos sometidos a su dominio. En las dos obras se establece una tensión que permite el contraste entre la idealidad de los discursos y las deficiencias humanas de los sucesos. Conviene recordar también la situación que provoca que los personajes de una y otra obra pronuncien las respectivas alocuciones. Don Quijote y Sancho, acogidos en una majada de cabreros — personajes del plano realista_, son convidados a cenar "con muestras de muy buena voluntad, con lo que tenían" (I, 11). En correspondencia con la visión idealista de don Quijote, el escenario es el adecuado para evocar el mito: los pastores han formado parte del tópico desde sus inicios con Hesíodo; la prodigalidad de los cabreros instaura el valor moral, la sancta simplicitas, que don Quijote exaltará, y las bellotas avellanadas ${ }^{8}$ puestas sobre la zalea al final de la cena serán el símbolo que le evoque el tópico y

\footnotetext{
${ }^{5}$ El investigador menciona a Virgilio, Égloga IV; Ovidio, Metamorfosis I; Séneca, Epistulae XC; fray Antonio de Guevara, Libro llamado Reloj de príncipes, cap. XXXI; Torcuato Tasso, Aminta; Luigi Tansillo, Il vendimmiatore (Traver: 88$)$.

${ }^{6}$ Según Levin (1968), las Metamorfosis fueron traducidas al inglés por George Sandy a principios del siglo XVII. Por su parte, Harold Bloom (2001) menciona las Metamorfosis como fuente de algunas obras compuestas por Shakespeare, aunque en ningún momento alude al mito en cuestión como antecedente del discurso de Gonzalo.

7 "Most of his exclusions [its inversions of European mores] follow Montaigne's list in the essay 'On the Cannibals', echoing the phraseology of Florio's translations...” (Levin: 125). "[...] la ideología de Montaigne impregna un famoso pasaje en que Gonzalo [...] habla de las características de una 'república ideal'. También ha sido ampliamente comentado el hecho de que el nombre de uno de los principales personajes, Calibán, es el anagrama forjado por Shakespeare a partir de caníbal, término que da precisamente al capítulo de los Ensayos de Montaigne que presenta, desde una admirativa, su visión acerca del 'hombre natural', y que constituye la fuente literaria del parlamento de Gonzalo" (Rossi). Ver también Cairncross (1970).

8 "Ya Hesíodo ( $f$ ca. S. VIII a. C.), que fue el [...] primer introductor del tópico en poesía, asoció indisolublemente la actividad ganadera a la Edad de Oro. Desde entonces, la poesía bucólica y, posteriormente, la novela pastoril recrean este mundo idílico [...] El poeta beocio también mencionó por primera vez las bellotas como alimento prototípico de la generación áurea, en los versos 8b-20 y 232-33 de su obra Los
} 
dispare su elocuencia, una construcción lírica más dedicada a enaltecer la Edad de Oro que a censurar los vicios de la de hierro. En relación con los motivos fundamentales del tópico de la Edad de Oro - comunismo primitivo, justicia social, automatos bios, denuesto de la riqueza, desprecio de la navegación-, Traver Vera juzga que el de don Quijote cubre todos, excepto el último (86-87). Aunque las lacras de "estos nuestros detestables siglos" quedan implícitas contrario sensu en las virtudes de los dorados, son tres los temas explícitos que el caballero critica: la estimación del oro en la edad de hierro, la ostentación en el vestido femenino y el riesgo que corre la honestidad de las doncellas cuando "con el celo de la maldita solicitud, se les entra la amorosa pestilencia" ( $Q$ I, 11$).{ }^{9}$ Crecida la malicia humana y con el fin de contrarrestar esas adversidades, se ha instituido la andante caballería, "para defender las doncellas, amparar las viudas y socorrer a los huérfanos y a los menesterosos" (I, 11). Don Quijote informa a los cabreros que ésa es la orden que profesa.

Con respecto a La tempestad, los hechos ocurridos en el Acto I han trazado un escenario de lucha por el poder del ducado de Milán. Un barco en el que viaja un grupo de nobles italianos, quienes aparecen en la Escena 1, ha naufragado cerca de una isla desierta, supuestamente ubicada en el Mediterráneo, cuyos únicos habitantes son Próspero, el legítimo duque de Milán, y su hija Miranda, además de algunos personajes de naturaleza extravagante: Calibán —anagrama de caníbal—, esclavo salvaje y deforme, hijo de una bruja, y Ariel, espíritu del aire. Con sus poderes, Próspero ha provocado el naufragio y decide que es el momento de enterar a Miranda y, en consecuencia, al espectador, de las circunstancias por las que se encuentran en esa isla y los motivos por los que perdió el ducado doce años atrás: el abandono de los asuntos mundanos ocasionado por su dedicación a las ciencias ocultas que le otorgan atribuciones extraordinarias, la consiguiente usurpación del poder por parte de su hermano Antonio y la sumisión a cargo de este último del ducado de Milán al rey de Nápoles, Alonso.

En la Escena 1 del Acto 2 reaparece, ahora en la isla, el grupo de nobles italianos, además de Gonzalo. El consejero del rey de Nápoles intenta consolar a Alonso, el monarca acongojado por la probable pérdida de su hijo Fernando a causa del naufragio. Por las condiciones mismas en que se encuentran, es natural que Gonzalo aborde el tema de la navegación, actividad no practicada en la Edad de Oro, según la versión ovidiana, y omitido en el discurso del caballero manchego ante los cabreros: "La desgracia que sufrimos — dice Gonzalo- no es única: cada día, las esposas de marinos, los dueños de barcos y los mercaderes también tienen motivo de dolor"10 (Shakespeare,

trabajos y los días". Virgilio (Geórgicas, I, 7-8) y Ovidio (Metamorfosis, I, 103-6) también se refieren a las bellotas (Traver: 86-87).

${ }^{9}$ Adolfo Sánchez Vázquez vincula el discurso de don Quijote con la situación de la España del siglo XVII: "Hay, pues, una crítica de la realidad tanto en el plano económico — la propiedad privada — como en el político-social de las instituciones: la Iglesia y el Estado; así como una crítica moral de la corrupción, las injusticias, el engaño y la deshonestidad" (2004: 21).

10 "El pino talado en sus propias montañas todavía no había bajado para visitar el mundo extranjero, a las límpidas aguas del mar, y los hombres no conocían más que sus propios litorales” (Ovidio: 70). 
2, 1). Pero es la posibilidad de establecer una colonia e iniciar una nueva vida en esa isla apartada de la civilización el motivo que inspira el discurso del consejero. Su disertación repite los temas que constituyen el tópico; establece de entrada el contraste entre el imaginado reino ideal y las costumbres vigentes, ${ }^{11} \mathrm{y}$, de igual manera que lo hace Montaigne en su ensayo, ${ }^{12}$ usa fórmulas de negación, y dado que él mismo se supone rey de ese mundo, ${ }^{13}$ el consejero no permitiría ni la traición ni la maldad —exhibidas a lo largo del drama por los nobles en pugna - ni las armas destructivas: "Would I not have..." (Tmp. 2, 1).

Ninguno de los discursos pronunciados por uno y otro personaje encuentra una respuesta adecuada por parte de los escuchas. En el Quijote, el malentendido se establece desde un principio; Sancho rechaza el ofrecimiento de su amo para que coma de su mismo plato y beba de la misma copa, signo cristiano y gesto caballeresco con los que don Quijote quiere manifestar la igualdad con su escudero, virtud que forma parte del locus comunis. ${ }^{14}$ Por su parte, el narrador informa que, habiendo presenciado tal discusión entre los recién llegados, "No entendían los cabreros aquella jerigonza de escuderos y de caballeros andantes" (I, 11). Terminado el discurso, la incomprensión proviene del narrador, quien, además, da cuenta del vacío en que cae la disertación de don Quijote: "Toda esta arenga (que se pudiera muy bien excusar) dijo nuestro caballero, porque las bellotas que le dieron le trujeron a la memoria la edad dorada, y antojósele hacer aquel inútil razonamiento a los cabreros, que, sin responder palabra, embobados y suspensos, le estuvieron escuchando". ${ }^{15}$ Sancho, por su parte — continúa informando el narrador-, se mantiene en silencio comiendo precisamente bellotas que, según el mito "caían del copudo árbol de Jove" (Ovidio: 70), y haciendo frecuen-

11 "GonZALO: En mi reino gobernaría al revés de las costumbres: no admitiría el comercio, ni los títulos de juez; estudiar sería algo desconocido, y no habría riqueza, ni pobreza ni servidumbre; no habría contratos ni herencias, ni tierras circunscritas por vallas, cultivos o viñedos; no habría metal, trigo, vino o aceite; ni ocupaciones: los hombres estarían siempre ociosos, y las mujeres también, aunque serían inocentes y puras; no habría monarquía...

$[\ldots]$

La naturaleza produciría de todo para todos sin sudor ni esfuerzo. Y yo prohibiría la traición, la maldad, las espadas, lanzas, puñales o máquinas de guerra: la naturaleza nos daría sus frutos para alimentar a mi pueblo inocente.

$[\ldots]$

Señor, mi reino sería tan perfecto que superaría a la Edad de Oro" (Shakespeare, [1611] 2011: 24).

${ }^{12}$ El ensayista construye un alegato en favor de la pureza de vida de los pueblos bárbaros de América; llega a oponer la "realidad" americana a la invención del propio mito, ya que aquélla "supera no sólo las pinturas con las que la poesía embelleció la edad de oro y todas las creaciones para representar una feliz condición humana, sino incluso el concepto y el propio deseo de la filosofia". Y, en un diálogo imaginario con Platón, Montaigne acude al tópico con el fin de describir las cualidades de esas naciones (Montaigne [1588] 2008: 268-269).

${ }^{13}$ La suposición es considerada por Levin (125) como "el infantil juego de 'Si yo fuera rey".

${ }^{14}$ El caballero hace alusión a la epístola de Pablo a los corintios (XIII); hace mención también al Evangelio de Lucas (XIV, 11): “- Con todo eso, te has de sentar, porque a quien se humilla, Dios le ensalza" $(Q \mathrm{I}, 11)$.

\footnotetext{
${ }^{15}$ Mis cursivas.
} 
tes visitas al zaque. Don Quijote no sólo ha equivocado la elección de sus escuchas, cabreros ordinarios, elevados por él a personajes del género bucólico, sino que también la solución a la malicia humana actual resulta desacertada. Pretender restaurar los valores perdidos de la Edad de Oro - sólo existentes en el mito- por medio de la caballería andante es ofrecer una solución inalcanzable a causa de la naturaleza ficcional del universo caballeresco, verdadero únicamente en su imaginación. En esta imposibilidad se inscriben los comentarios críticos del narrador. ${ }^{16}$

La escena correspondiente en La tempestad presenta una tensión dramática sostenida entre el consejero real junto con otros dos nobles, Adrián y Francisco, por un lado, y Sebastián y Antonio, por otro, quienes crean en apartes y en interpelaciones directas un contrapunto burlesco para desacreditar el mensaje de aliento que Gonzalo dirige al rey Alonso. Por su parte, el rey, sumido en su pena, le pide que calle o no atiende sus palabras. El antagonismo entre los nobles pronto surge con una discusión sobre la reciente boda de la hija de Alonso con el rey de Túnez, de donde se dirigían de vuelta a Nápoles en la nave que naufragó. En esta atmósfera anímica poco propicia, Gonzalo da inicio al tema del reino ideal con un discurso contradictorio, ya que se supone rey — "Alteza, si yo tuviera que colonizar esta isla [...] si fuese el rey de esta tierra, ¿qué haría yo?"- y finaliza su primera intervención proponiendo que "no habría monarquía..." Las nuevas burlas señalando la contradicción del consejero no se hacen esperar. Sebastián señala: "Aunque haya dicho que él sería el rey". Y Antonio comenta: "Para el fin de su reino se olvida de sus principios". ${ }^{17}$

La alocución de Gonzalo, parodiada con mofa por los nobles, finaliza con un estruendoso fracaso al ser desacreditada también por el rey, a quien iba dirigida:

\section{SEBASTIÁN}

¿Sus súbditos no se casarían?

ANTONIO

No, todos vivirían en el ocio: todos maleantes y todas putas.

GONZALO

Señor, mi reino sería tan perfecto que superaría a la Edad de Oro.

SEBASTIÁN

\footnotetext{
${ }^{16}$ Sánchez Vázquez hace una lectura optimista de la propuesta cervantina: "El fracaso de una utopía determinada, concreta, no condena al fracaso a toda utopía. Lo que Cervantes insinúa, y ésta es otra de las grandes lecciones de El Quijote [sic], es que una utopía como la suya fracasa si no se dan ciertas condiciones para su realización. En suma, la gran empresa quijotesca de realizar el bien fracasa cuando las ventas se toman por castillos, cuando sólo se dispone de un jamelgo escuálido, cuando se actúa en una sociedad jerárquica y cerrada y se lleva a cabo esta noble tarea solitariamente, sin contar con la cooperación, la ayuda y la solidaridad de otros" (2004: 22). "Utopía fue traducida al español en 1637, si bien de modo incompleto" (Martínez: 2). De ello se deduce que Miguel de Cervantes no pudo haberla conocido.

17 "GONZALO: Y yo prohibiría la traición, la maldad, las espadas, lanzas, puñales o máquinas de guerra", restricciones que resultan contradictorias con los principios inicialmente declarados con respecto a la ausencia de autoridad: "no admitiría [...] los títulos de juez [...]; no habría monarquía..." (Shakespeare [1611] 2011: 24).
} 
¡Que Dios salve a su Majestad Gonzalo!

ANTONIO

¿Que viva Gonzalo!

GONZALO

Y... ¿Me escucha, Majestad?

ALONSO

Basta, por favor, basta; no dices más que tonterías (Shakespeare [1611] 2011: 24-25).

Así, en el drama de Shakespeare, no sólo por sus propias contradicciones y la recepción irónica de que es objeto el discurso de Gonzalo, sino porque los mismos acontecimientos dramáticos, vistos a la luz del mito de las edades del hombre, se presenta como una de las peores lacras de la de hierro la lucha por el poder entre miembros de la nobleza. De este modo, la utopía referida por el consejero regio choca con el discurso descalificador de los cortesanos maquiavélicos - como los califica Harry Levin (126) - y contrasta con la realidad humana representada en el drama shakespeareano; en términos bajtinianos, establece una conflictiva relación dialógica con la visión opuesta del otro. ${ }^{18}$

Finalmente, quisiera destacar algunos temas que me parecen fundamentales con respecto a la reescritura de este locus comunis en la obra narrativa y en la dramática escritas por esos dos genios del siglo XVII. En una y otra se propone que las condiciones ideales que representa el mito resultan incomprensibles para las generaciones presentes. Por un lado, sólo han tenido existencia en una edad humana desaparecida sin remedio, un illo tempore irrecuperable, al que don Quijote, sin embargo, quiere dar vigencia; por otro, podrían ocurrir únicamente fuera de la civilización como se la conoce, en un lugar nuevo y apartado, semejante a la isla deshabitada que inspira la alocución de Gonzalo, según el patrón de la Utopía de Tomás Moro, ${ }^{19}$ que, como traduce Quevedo: "Utopía: no hay tal lugar..." ${ }^{20}$ No obstante, el mito, aunque ficticio, posee una fuerte carga simbólica:

18 "Cualquier palabra concreta encuentra el objeto al que quiere echar una luz ya discutido, evaluado, cubierto de una especie de bruma o, al contrario, alumbrado por la luz de palabras ajenas. El objeto aparece como penetrado de ideas generales, puntos de vista, apreciaciones ajenas, de acentos de otros. La palabra dirigida hacia su objeto entra en ese medio dialógicamente agitado y tenso de palabras, valores y acentos de otros, se funde con unos de ellos, rechaza otros, se cruza con terceros; todo lo cual contribuye a constituir la palabra, a complicar su expresión, influye en su apariencia estilística" (Bajtín, apud. Bubnova: 94).

19 “"...] Tomás Moro, humanista, religioso y político inglés, [...] en 1516 propuso un patrón literario que sería aceptado y seguido por otros muchos autores para así constituir el género utópico. Su obra De optimo reipublicae statu deque nova insula Utopia... El primero de ellos encierra un diálogo de carácter crítico con la Inglaterra (y por extensión con la Europa), de la época; en el segundo, el diálogo se centra en la descripción de una sociedad ideal que habita una lejana ínsula a la que el protagonista, Rafael Hytlodeo, llega tras un naufragio" (Martínez: 2).

20 “[...] en el prólogo a la versión, expurgada, que en 1627 hizo Gerónimo Antonio de Medinilla y Porres de la obra de Tomás Moro" (Imaz: 7). Por otro lado, debido a que en La tempestad hay una clara influencia del ensayo "De los caníbales" de Montaigne, a que se ha vinculado el drama con relatos de viajes y porque se hace mención en él a ciertos vocablos oriundos del Nuevo Mundo, se considera que la obra está permeada por el imaginario europeo sobre América (cf. Fry: 29-41). 


\section{$54 \square$ EL MITO DE LA EDAD DE ORO EN EL QUIJOTE Y EN LA TEMPESTAD}

el deseo y la aspiración humanos de condiciones morales y materiales superiores. Ése sería el valor de su presencia en ambas obras y, a pesar de la incomprensión en que cae, estaría apelando a la sensibilidad del lector o del espectador. Pero ninguno de los textos peca de ingenuo y, a la vez y paradójicamente, al contrastarse el mito con la situación narrativa o dramática acentúa la decadencia de los tiempos históricos.

Importa matizar también las diferencias en la naturaleza de uno y otro discurso. El de don Quijote no sale de los términos de la ficción: el mito al que se refiere, así como la caballería andante que profesa y propone como restauración de la edad dorada, pertenecen al reino de la fantasía y, a lo largo de todo el relato, las reglas de esa orden practicadas por el manchego prueban su fracaso, hecho que lo convierte en héroe de la Modernidad. ${ }^{21}$ Además, no obstante el dialogismo característico del Quijote, el discurso en cuestión podría considerarse monológico — no hay posibilidad de establecer diálogo con los presentes: Sancho y los cabreros-; de allí su inadecuación. ${ }^{22}$ Sin embargo, es el narrador quien, con sus comentarios irónicos, instaura la tensión dialógica. Por su parte, el del consejero del rey de Nápoles se inscribe en el reino de la utopía, ya que se presenta como programa político en condiciones que permitirían su ejercicio. Pero el deseo de innovación choca contra los intereses inmediatos de los demás personajes.

Y, por último, un comentario sobre los discursos como piezas literarias: además de que la alocución de Gonzalo es más breve que la del caballero manchego, por un lado, carece de la convicción y el aliento lírico que caracterizan a la de don Quijote y, por otro, las negaciones, prohibiciones y contradicciones del consejero del rey le restan fuerza argumentativa.

\section{Obras citadas}

Bajtín, Mijail. 1986. Problemas de literatura y estética. La Habana: Arte y Literatura.

Bloom, Harold. 2001. Shakespeare: la invención de lo humano. Trad. Tomás SEGovia. Bogotá: Norma.

Bubnova, Tatiana. 1980. "El espacio de Mijail Bajtín: filosofía del lenguaje, filosofía de la novela”. Nueva Revista de Filología Hispánica, vol. XXIX, núm. 1. México: Colmex. Pp. 87-114.

21 " [...] la típica oposición espacial interior-exterior que el héroe cabal itinerante, proverbialmente Amadís, lograba resolver en una adecuación del primer término al segundo por el ejercicio de sus aptitudes bélicas y su palabra, en el caso de Don Quijote, el héroe de la Modernidad, es resuelta por las fuerzas antagonistas al caballero mediante una profanación, acción compulsiva por irreductibilidad al cambio, del espacio exterior-ahora-Edad de Hierro, sobre el espacio interior-entonces-Edad de Oro, causando el desengaño y el silenciamiento del héroe" (Lastra: 409).

22 "El monologismo, que nace del desencuentro entre el inflamado lenguaje del héroe y el lenguaje del mundo, marca por supuesto la novela y su propuesta de modelación, pero no marca la relación entre los dos personajes centrales" (Jofré: 117). 
CAIRncross, Andrew. 1970. "Shakespeare and the Golden Age". The South Central Bulletin, vol. 30, núm. 4. Baltimore: The Johns Hopkins University Press. Pp. 173-175. <www.jstor.org/stable/3187984>.

CERVANTES, Miguel de. El ingenioso hidalgo don Quijote de la Mancha. Ed. Centro Virtual Cervantes.

$<$ http://cvc.cervantes.es/obref/quijote/edicion/parte1/parte02/cap11/default.htm>. FrY, Charles. 1979. "The Tempest and the New World". Shakespeare Quarterly, vol. 30, núm. 1. Washington: Floger Shakespeare Library. Pp. 29-41. Consultado: 12 de marzo de 2012. <http://www.jstor.org/stable/2869659>.

Hesíodo. 1976. Teogonía, Los trabajos y los días, El escudo de Heracles, Idilios de Bión, Idilios de Mosco, Himnos órficos. Pról. José Manuel Villalaz. México: Porrúa ("Sepan Cuantos...", núm. 36).

ImAZ, Eugenio. 1975. "Estudio preliminar" a Utopias del Renacimiento: Moro, Campanella, Bacon. 4a. reimp. México: FCE.

JOFRÉ, Manuel. 2005. "Don Quijote de la Mancha: dialogismo y carnavalización, diálogo socrático y sátira menipea". Revista Chilena de Literatura, núm. 67. Pp. 113-129. Consultado: 20 de abril de 2012.

$<$ http://www.scielo.cl/scielo.php?script=sci_arttext\&pid=S071822952005000200 008\&lng $=$ es\&nrm $=$ iso $>$.

LASTRA, Silvia Cristina. 2008. "De Amadís al Quijote: la reconversión del código justiciero". Amadís de Gaula: quinientos años después. Estudios en homenaje a Juan Manuel Cacho Blecua. Ed. José Manuel Lucía Megías y María Carmen MARÍN PINA. Alcalá de Henares: Centro de Estudios Cervantinos.

LeVIn, Harry. 1968. The Myth of Golden Age in the Renaissance. Bloomington / Londres: Indiana University Press.

MARAVALL, José Antonio. 1976. "La utopía del buen discurso". Utopía y contrautopía en el Quijote. Madrid: Ediciones Pico Sacro. Pp. 169-235.

MARTíneZ, José Carlos. 2005. "Historia de la utopía: del Renacimiento a la Antigüedad". Espéculo: Revista de Estudios Literarios (digital), núm. 30. Consultado: 15 de marzo de 2012. <www.ucm.es/info/especulo/numero30/liutopic. html $>$.

Montaigne, Michel de. 2008. "De los caníbales". Ensayos t. I. 9a. ed. Ed. María Dolores PicAzo. Trad. Almudena MontoJo. Madrid: Cátedra (Letras Universales). Pp. 263-278.

Ovidio, Publio. 2001. Metamorfosis. 3a. reimp. Trad. Antonio RAmíreZ DE VerGer y Fernando NAVArRo Antolín. Madrid: Alianza Editorial. (Clásicos de Grecia y Roma)

Rossi, Ana María. 2010. "Shakespeare: la presencia de Montaigne y Ruy Díaz de Guzmán en La tempestad, su última obra”. Temakel. Consultado: 1 de abril de 2012. $<$ http://www.temakel.com/node/76>. 
SÁnchez, Adolfo. 2006. "Don Quijote como utopía”. Casa, vol. 46, núm. 243. La Habana: Casa de las Américas. Pp. 119-123.

. 2004. "Don Quijote como utopía", Revista de la Universidad de México, núm. 6. México: UNAM. Pp. 18-23.

ShaKespeAre, William. 2011. La tempestad. Trad. Alfredo Michel Modenessi. Ms. libreto original del traductor, montada en el teatro Juan Ruiz de Alarcón de la UNAM, México D. F.

ShaKeSPEARE, William. The Tempest: Entire Play. <http://shakespeare.mit.edu/ tempest/full.html>.

STAGG, Geoffrey. 1985. "Illo tempore: Don Quijote's Discourse on the Golden Age and its antecedents". La Galatea de Cervantes cuatrocientos años después (Cervantes y lo pastoril). Ed. Juan Bautista Avalle ArCE. Newark: Juan de la Cuesta. Pp. 71-90.

TraVER, Ángel. 2001. "Las fuentes clásicas en el 'Discurso de la Edad de Oro' del Quijote". Actas de las Segundas Jornadas de Humanidades Clásicas. Almadralejo: I. E. S. Santiago Apóstol. Pp. 82-95. Consultado: 4 de abril de 2012. $<w w w . d i a l n e t . u n i r i o j a . e s /$ servlet/fichero_articulo?codigo $=2676794>$.

Virgilio, Publio. 1997. Bucólicas, Geórgicas. 4a. reimp. Introd., notas y trad. Bartolomé Segura Ramos. Madrid: Alianza Editorial. (Clásicos de Grecia y Roma) 